10 years ESJ

Special edition

\title{
Adaptation Strategies: Aesthetics of the Linguistic Codes Used by Drug Addicts in Portugal
}

\author{
José Vicente, Social Work PhD
}

CIES - ISCTE - IUL / ESECS - Polytechnic Institute of Leiria, Portugal

Fernando Magalhaes, Anthropology, Museology, and Cultural Heritage PhD

CRIA - ISCTE - CIEQV / ESECS - Polytechnic Institute of Leiria, Portugal

Doi: $10.19044 /$ esj.2021.v17n26p1

Submitted: 18 March 2021

Accepted: 19 May 2021

Published: 09 August 2021
Copyright 2021 Author(s)

Under Creative Commons BY-NC-ND

4.0 OPEN ACCESS

Cite As:

Vicente J. \& Magalhaes F. (2021). Adaptation Strategies: Aesthetics of the Linguistic Codes Used by Drug Addicts in Portugal. European Scientific Journal, ESJ, 17 (26), 1.

https://doi.org/10.19044/esj.2021.v17n26p1

\section{Abstract}

Daily continuous drug use becomes a chronic disease, and this causes the person to lose control over his actions and over his own life. The most used nomenclatures/terminologies when referring to drug users is "addict". The desire to use drugs overrides all the activities and responsibilities that the drug addict must carry out in his daily life. The physical and psychosocial destruction of the drug user is quick and visible to all those around him and who lives with him daily. In Portugal, drug addicts, despite knowing that they are not criminalized for drug use, know and feel that this is not a socially accepted practice. In this sense, one of the ways that these people defend themselves from social criticism or judgment is through the elaboration of the perceptible linguistic signs and codes, which is understandable only by the drug addicts. In this research, the analysis dimension consisted of understanding and decoding these linguistic codes and to perceive the main reasons that are inherent to their use by drug addicts. According to the reports of drug addicts, it was possible to decode these linguistic codes of drug addicts and translate them into a language that can be accessible to the Portuguese society in general, and for all those who develop their professional practices with drug addicts. To carry out this research, the qualitative methodology was 
used, which is centered on a case study. Semi-structured interviews were used as a data collection technique. For data analysis, the content analysis was utilized.

Keywords: Adaptation strategies, linguistic codes, drug addicts

\section{Introduction}

Human society knows that drug addiction is a disease. However, drug use or the way consumers organize and relate to each other and to others outside their community continues to be considered deviant and not a socially accepted behavior. As a tactic of protection against stigmatization, discrimination, and prejudice on the part of the population, drug addicts use, in their daily experiences, behaviors and linguistic codes which is only known and understood by them. This behavior is a strategy through which the drug addict wants to avoid his exposure to others as a chemical addict.

The reasons to justify the drug use can be multiple and varied, and they are anchored in different life trajectories of the drug addicts. In this context, the social interventionist must have the capacity to listen to the recovering drug addicts, understand their linguistic codes, their life stories, their perspectives, and desires for the future in order to make the social intervention effective and efficient.

Some of the linguistic expressions used by drug addicts emerge within a specific socio-cultural framework, i.e., a small Portuguese community. They do not have English translation, so they are retained in their original language. This is why they are presented in this research in italics.

The research also followed a qualitative methodology based on a case study that was carried out using semi-structured interviews. This was applied to nine people subject to the drug addiction treatment, aged between 33 and 49 years. All the research subjects belonged to the same group and consumption environment, having maintained drug use on a regular basis for a period over 10 years. Furthermore, the perspectives of nine interviewees are presented. Respondents are identified by the acronym E0_Nome fictitious in order to preserve their anonymity, and this is also part of the interviews order.

The qualitative methodology was chosen due to its flexibility and adequacy to the relatively unexplored character of this social phenomenon. For the analysis of the data, an inductive and comprehensive approach was used that provided a clear understanding of the meanings and senses hidden or less visible in the interviewee's reports.

The purpose of this study was to obtain an in-depth knowledge about the linguistic aesthetics and the communicational codes used by drug addicts in their social context. 
This research is structured into two parts. In the first part titled "Drug Addiction and Withdrawal Syndrome: Some Reflections", the theoretical perspectives are combined with the meanings attributed to the concepts of drug addiction and withdrawal syndrome. This is obtained from the perspective of the scientific literature and from the interviewees.

In the second part titled "Aesthetics of behaviors and language in Drug Addiction", it is important to understand the social images built on by drug addicts undergoing treatment. The encounters and mismatches between their linguistic codes and those used by the Portuguese society are also a theme to be worked in the second part of the research.

\section{Drug Addiction and Withdrawal Syndrome: Some Reflections}

The definition of drug addiction cannot be based solely on the idea of the chemical dependence on psychoactive substances. Therefore, the intention and focus of this research are centered on the consumption, on the abuse of the psychoactive substances, and on the impact that this addictive behavior has on the lives of its consumers during and after the treatment process in the therapeutic community. In this context, the World Health Organization (2002) defined drug addiction as a state of chronic intoxication of the organism that is harmful to the individual and to the society. It is produced by the administration of a "drug" (natural or synthetic) in the body and is characterized by an inescapable desire or need to continue.

In 2010, WHO redefined drug addiction as "a set of behavioral, cognitive, and physiological phenomena that are developed after repeated use of a substance, and that typically includes a strong desire to take the drug, difficulties in controlling its use, persisting in its use despite its harmful consequences, a higher priority given to the drug use than to other activities and obligations, increased tolerance, and sometimes a state of physical deprivation" (WHO, 2010).

Currently, it is necessary to look at drug addiction as a disease or as an inability of the consumer to preserve his own health. The problem of drug addiction remains a major concern at the individual, family, and community levels. It is "a biopsychosocial phenomenon situated at the meeting point of multiple dimensions that interpenetrate in human life, resulting from the encounter of a toxic product (the drug), an individual (and his personality), and a sociocultural moment, i.e., from a social and cultural context located in time" (Fernandes, 2007, p.20).

Drug addiction generates permanent discomfort, impulsivity, and anxiety in the consumer. This often leads him to lose the notions of what is right or wrong from an ethical point of view. The longer the consumption period, the greater the dependence and the amount of drugs consumed by the addictive person. According to Lucchini (1985), "drug addiction is a foreign 
condition for the traditional societies which only emerges as a problem in the contemporary societies" (p.138). This statement is supported by Marques (2008) who reinforced the thesis that in traditional societies, there has always been a diversified use of drugs. Marques opined that "some today is prohibited, but under a symbolic and socially framed ritualization. In most situations, this is done as support for religious ceremonies and magical practices" (Marques, 2008, p.19).

However, the use of drugs, regardless of the purpose for which they are used, never made them a product to be seen as primary, essential, or legal. Although the growth of the pharmaceutical industry and the hegemony of the biomedical model have boosted the sale of various types of drugs, which are used strategically and in a dominant way to obtain profits. However, there has been some caution in regulating and controlling their acquisition. Many of the drugs used repeatedly by modern medicine are prepared and designed by chemical compounds, which when used without a prescription can be more dangerous than the use of illicitly manufactured drugs.

The consumer of psychoactive substances uses drugs to relieve his momentary pain, without thinking that he or she is increasing his addiction and destroying his health. Nevertheless, the relationship between the "social appreciation of health and the adoption of behaviors that protect it, as expected, is not always linear. Other variables make this equation more complex and, in drug use, they can go through pleasure, imitation or rituality" (Silva, 2011, p.43).

Drug addiction makes the person look at the drug as an essential good. Nothing is more important in the daily life of a drug addict than having the amount of drug that he or she needs to consume. Drug addiction turns the lives of users into a daily struggle over the dose they must consume. He or she exhibits a permanent desire to consume drugs, in which dissatisfaction becomes uncontrollable. This result in a lack of drugs/withdrawal syndrome which is a torment that can trigger the person to do anything to fulfill their need. For a drug addict, there are no limits and everything is possible to be done, provided that in return he or she receives money so as to obtain the amount of drug necessary to overcome the withdrawal syndrome. This is nicknamed in common language as jargon "matar a ressaca"1.

\section{The Withdrawal Syndrome (or withdrawal state)}

The withdrawal syndrome can be defined as "a set of symptoms grouped in different ways and whose severity is variable. It occurs because of an absolute or relative withdrawal of a psychoactive substance consumed for

${ }^{1}$ Term used by the Portuguese drug addicts when they refer to "ending the withdrawal syndrome". See the final glossary. 
a long time. The onset and evolution of the withdrawal syndrome is limited in time and depends on the category and dose of the substance consumed immediately before stopping or reducing consumption. The withdrawal syndrome can be complicated by the convulsions occurrence" (SUS, 2015, p.2).

Sónia (42 years old), one of our interviewees, defines this problem in simple terms: "drug addiction is an animal (bicho) that is within us that does not leave us with feelings, emotions, and thoughts. We lose control, we lose the will to do everything, to eat, to sleep, to have sex, to be with others, to laugh, to walk, everything. We just want to consume drug, send a kick (mandar um chuto), smoke a Chinese (fumar uma chinesa), or smoke a pipo. It's the only thing that can make us feel good when we are having a hangover. When we are in that state, they can even offer me the best car in the world, invite me to go to a big party, spend a vacation in the most paradisiacal place in the world; if you don't have a drug to use, it is useless. But possibly, the car would be accepted and I could always sell it to buy some grams and consume" (E07_ Sónia).

This report confirms drug addiction as "a disease, perhaps one of the most serious, of this century (XXth century). It is a global disease that compromises the person's physical life, as well as the psychological and social dimension of the human being. The drug addict is in constant suffering" (Andrade, 1994, p.1).

The drug addicts, during consumption, also have no limit. Since their only desire is to relieve pain, anguish, anxiety, and frustration resulting from the withdrawal syndrome, they do not look for ways to achieve the ends. This makes them consume all kinds of psychoactive substances. Physical pain, diarrhea, cold sweats, vomiting, insomnia, among many other physical and emotional symptoms, cause reactions that they have difficulties in controlling.

For a heroin user, "the hangover" is a moment of complete uncontrollability. Nothing will be an obstacle, barrier, or impediment to finding strategies, skills, and ways to get the money to buy the drugs necessary to fight the withdrawal syndrome and to be without drugs for a few hours.

A drug addict who "hangs out" suffers physical and emotional pain, fears, and anguish. This is as a result of the inner revolt of knowing that there is a product that removes that suffering and sometimes he cannot acquire it. Nonetheless, the "hangover" is a difficult and extremely painful time. Life is not easy for the heroin addict or any other drug addict. The symptoms of a hangover include muscle spasms, vomiting, diarrhea, a runny nose, insomnia (so that it is impossible to sleep), chills, and sweat. The "cold" hangover lasts for about a week, but the strong desire to start consuming again and the inability to sleep can last for years (IDT, 2002). 
There are some testimonies from Portuguese public figures who even claim that the withdrawal syndrome is perhaps one of the biggest nightmares that they have ever lived. The famous Portuguese singer and interpreter, Lena de Água, in an interview to a radio station (Rádio Renascença) in 2016 describes abstinence as "something absolutely unbearable. You don't have the strength to stand. Legs are shaking. The stretches - tau, tau tau! - in the calves. Cold sweats. Oh, my God, my God, my God, I just felt like throwing myself to the ground!" (Água, 2016).

Each drug user, depending on their advanced state of drug addiction, can endure longer or shorter periods without using drugs. On the other hand, the amount of drugs needed to stop the withdrawal syndrome depends on the years he or she uses it and the amount that the drug addict consumes throughout his life.

There is no drug addict, regardless of their social status, age or physical capacity, who can remain static in a "hangover" moment without trying to find a solution to acquire drugs to stop the withdrawal syndrome.

António (40 years old) who is another of our interviewees says: "the hangover is the worst thing I've ever been through. When we are hangover, we are not able to do anything; at that moment the only thing you think about is going to buy drug (pó) $)^{2}$. If you have money, you don't get hangover, because before you start the hangover, you're going to the Dealer ${ }^{3}$ right away, but if you don't have money you have to do for life. You either do it for life or you have someone to give you (money), or lend, but this only happens a lot at the beginning of starting to consume, because afterwards you have already deceived everyone and nobody gives you or lends you anything, you do anything to get money, even anything, when you are really clinging (agarrado), you're kicking, you want money to buy the cena ${ }^{4}$ and "kill" the hangover" "(E06_António).

Drug addiction is one of the biggest health problems that has arisen in the last 40 years in Portugal. The harmful consequences of drug use on health, and in all dimensions of the lives of consumers and their families, have caused civil society organizations and policy makers to start working together. The objective was to develop strategies, legislation, and services to combat this social problem as their social genesis.

\footnotetext{
${ }^{2}$ Dust or pó in Portuguese is synonymous of heroin, and it is used in slang language by drug addicts.

${ }^{3}$ Name given to the person selling the drug.

4 The Portuguese term "cena" is used to replace that of "drug".

${ }^{5}$ Killing the hangover is a term used among drug addicts when they refer to stopping the withdrawal syndrome.
} 


\section{Aesthetics of the Behaviors and Language in Drug Addiction}

Drug addiction is one of the most serious problems in contemporary societies. This has generated a particular way of living among drug addicts. A drug addict learns, over the years of the psychoactive substance's consumption, a coded language to refer to the daily life actions inherent to this culture.

In the 90s of the last century, the fashion industry took advantage of the image and degraded behaviors associated with people addicted to drugs to create a new style in the way of dressing and living. The idea came from a professional fashion photographer, Corinne Day, who was responsible for the emergence of the style called "heroin chic".

The "Heroin chic" was a style that showed a clear glamorization of drugs. In the book titled "Fashion, Desire, and Anxiety: Image and Morality in the 20th Century", Rebecca Arnold mentions that this fact has become so serious that the President of the United States of America (Bill Clinton) and other international personalities were concerned with this drug's glamorization. This is due to the negative and abusive way in which young people acquired the wrong idea about the drug use.

The "heroin chic" style had a great resonance in the press of the mid90s within the last century. The promotion of the drug use associated with cinema and fashion was at the heart of the media's concern at the time. Among other articles, on August 8, 1996, the L. A. Times newspaper wrote an article about the issue "heroin chic" titled "Why Dole Frowns on Fashion". In this newspaper article, the "heroin chic" is the look. This is the fashion fueled by the success of the movie "Trainspotting", and the renewed use of the drug to a high standard is now associated with fashion and glamor. This new style had a significant impact on the assumption of a new identity by the drug addicts, not only in the way they began to present themselves visually, but also in a new posture.

When the drug addicts use drugs, in addition to their own language, they also develop their own style and image that they project to the other members of their group. This aesthetic component, although at times degrading and decadent in the eyes of those outside this relational sphere, is a primary tool for communicating and establishing close relationships with other drug addicts and traffickers.

"The different forms of communication are apprehended throughout the life stories of each subject, influencing how each one acts in relation to the others. The messages apprehended by each communicator influences the way they will communicate with each other presently, as it predisposes them to a

\footnotetext{
${ }^{6}$ The term "glamorizing drugs" is commonly used by the drug addicts to describe the positive aspects of drugs such as quality, quantity, and symptoms.
} 
larger set of signs and messages, which will be interpreted and shared by both" (Ceron, 2012, p.28).

Starting with verbal language in the context of drug addiction, there is a usage of terms that are only perceivable to consumers. Therefore, the use of a specific code has main reasons because the illegality inherent in drug trafficking and the fact that the consumption of psychoactive substances is socially objectionable.

Drug addiction problem is a world full of learning for any social worker. The recognition of language codes allows the social worker to broaden the understanding of the reality of the drug addicts undergoing treatment. Understanding these codes allows a better comprehension and analysis of their experiences. The social intervener is thus equipped with knowledge to intervene. One of the fundamental principles of the responsibility of the social worker is to perceive the reality objectively and to identify the means to work in order to reach the objective that was proposed (Lacerda, 2014, p.31).

When faced with situations of drug use, purchase, and sale, some of the terms used are only perceived by active consumers, recovering consumers or people who work directly with this type of audience. These professionals reach this coded model of communication throughout their professional activity.

The art of listening means having patience and tolerance with the others. This means that it is necessary to perceive, to understand and, above all, to respect the divergent opinions. Accordingly, drug addicts undergoing treatment will be able to comply with rules and adopt new behaviors.

In Portugal, the population generally refer to people who consume psychoactive substances abusively and continuously with pejoratives linguistic terms such as drogado, toxicodependente, dependente químico or adito which denote strong negative meanings. On the other hand, drug addicts and recovering drug addicts substitute those terms for "agarrado", "carocho", "janado", and "kafunfeiro". This means that within the group, no one refers to the other as an addict. When they talk to each other about themselves, they mainly use the terms "carocho" and "janado".

To clarify and exemplify these linguistic codes, the recovering drug addicts were asked to elucidate more by saying some phrases they used in their daily lives which a non-addict may not understand immediately.

One of them, Manuel (37 years old), says: "when we were talking to each other in a public place and we wanted to consume drug, it was enough to say to the other "Boot dar um ticket", when saying this, the other person immediately understood the message, since those who were outside did not understand anything... It was a way to disguise" (E09_Manuel).

${ }^{7}$ Let's go to use drug. 
Another of the interviewees, António, describe a completely different example of the linguistic code. The words used in the drug addiction context are different, but the meaning is the same. Therefore, António use a different terminology to describe the same action, which is only understandable by the drug addicts.

"I never really liked to give the flag ("Eu nunca gostei de dar Bandeira" ${ }^{8}$. When I was with colleagues and we were to consume drugs, I used the expression "I'll give in fruit" ("vou dar na fruta") many times. Today, to refer to someone who has been consuming, I use the term "clinging", or "beetle" ("agarrado", ou "carocho")" (E06- António).

There are many designations to say, "let's go or I'm going to consume drug" ("vamos, ou, vou consumir") such as: let's hit it, even though we give it a kick/peak or broth, smoke a Chinese, give it a beer ("vamos dar nela, embora dar um chuto/pico ou caldo, fumar uma chinesa, dar um pipo"). All these denominations serve as a call for the action to consume drugs.

Jargon and proper expressions among drug addicts have a greater impact whenever the addict moves to a stage of complete delivery to the consumption of psychoactive substances. The existence of a common language, both for the different types of drugs and for their consumption, works as a way of integrating these individuals in the group of consumers. It helps them to relate and interact with each other. If the terms Heroin, Cocaine, Hashish, herb, etc. are socially used to refer to different types of drugs, the interviewees refer to them as "chestnut, powder, kafufo, horse, and poison" ("castanha, pó, kafufo, cavalo, veneno") for heroin. This is evidenced by the interviewees Madalena and Sónia:

"When I was consuming drug, I never asked anyone, do you have heroin? From time to time, I said do you have "heroa"? But almost always I used the terms, do you have "pó" or do you have "castanha"? (E03_ Madalena).

"I almost always said "castanha" or "cavalo". I never used the term "heroin", only the people who don't consume it say heroin" (E07_Sónia).

Cocaine is referred to by drug users as "coca, branca or gulosa". For most of the participants in this research, the most used term is "branca".

I usually said "branca" when I wanted to talk about cocaine. In the waves of the consumption, we all said "branca" or "coca" (E02_João).

\footnotetext{
${ }^{8}$ Bandeira is the Portuguese jargon term to describe an attitude or action that makes people around us to understand what is happening. When someone is saying, publicizing, gesturing, or having a behavior that makes the secret to those outside your group known, it is giving the flag. In the informal online dictionary, this term is classified as "showing what you should hide; expose something that shouldn't show".
} 
"When I was using drugs, I heard everyone saying "branca"! Sometimes, some people said "coca", but that expression was mostly used by newbies or people who weren't too attached" (E09_ Manuel).

Hashish is usually called "xito", "xamon", "ganza" or more similar to its real name "haxe". To describe the action of consuming this drug, consumers usually mention smoking "uma ganza, uma broca, um charuto or um carapau." The term "charro" is the most recognized by anyone. However, it is not the most used among consumers.

According to the consumers, drug dealers are also nicknamed in different ways. One of the most well-known names is "Dealer". Nevertheless, there are other names like "Paiador" or "Passador". Although, "Dealer" is the term most used by consumers according to the reports of former residents of the therapeutic community.

I used to call "Dealer", or even say anything, saying: "I'm going to buy a fourth or a half gram" (E08_ Nuno).

On my side, I said "Dealer". I almost always went to the same places to buy drug, and there was always dust "pó". I just said that word if I realized that someone was looking for drug. At that time, I was able to ask: are you looking for dust "pó"? Do you want me to introduce you to the "dealer"? But I did this because it was a way of taking some drug doses (traços $\left.{ }^{9}\right)$ " (E04_ Rui).

Generally, the knowledge and curiosity of society about the language used by drug addicts during their consumption trajectory could be a sufficient reason for carrying out this research. However, the intention of this research lies in the need to contribute to the knowledge of the language codes. This can be achieved as professionals develop their practice with the drug addicts, so that their action is more effective.

The understanding of the drug addict's behaviors and the ability of the technician to help them requires communication skills between the parties. These professionals must be permanently attentive to a series of words/terms and behaviors that drug addicts develop in their illness context. All the professionals have an advantage to understand the language codes used by drug addicts whenever they must help them to recover their health, their image or defend them in court cases.

It is considered that the ease of communicating properly, before society in general and communities, depends on multiple factors such as the personality of the communicators whether professional or the drug user, the influence of the family, and the cultural environment. These are central strands

\footnotetext{
${ }^{9}$ To keep a few "traços" means that after indicating the Dealer to buy Heroin or Cocaine, the person who pays for the product gives him a small quantity of drugs as a bonus.
} 
that influence the way of communicating and are very difficult or practically impossible to change (Silva, 2008).

Understanding the jargon increases the ability to perceive and verify the socio-relational dynamics generated among drug addicts undergoing treatment and between the professionals of the teams that intervene with it.

\section{Conclusion}

The acquisition of comprehension skills by professionals based on the codes used by drug addicts allows them to decipher and to understand their problems. Through this way, it is possible for the professional to understand whether drug users are adopting new behaviors, changing attitudes, and conduct, or if they inversely continue to value drugs, experiences around consumption or whether the will to consume them prevails. The process of recovery can take place when drug addicts start to abandon the language and the routine that they acquired during the period that they used drugs.

Drug "glamorization ${ }^{10 "}$ is a habit that occurs when drug addicts come together in dialogue with each other. Through these attitudes and behaviors, it is possible to have a more accurate perception of all the behaviors and linguistic codes that help them to communicate with each other without those around them being able to understand them.

The messages and conversations that drug addicts undergoing treatment have with each other in the therapeutic community serve the social worker and other members of the technical staff as instruments of assessment, which is used for measuring the behavior and attitudes of the drug consumer. Through these, the technicians analyze the level of will and the motivation that addicts must have to free themselves from the bonds of the drug.

\section{Final Glossary with the Jargon Words and Expressions}

Agarrado", "carocho", "janado", "kafunfeiro" - drug addict

Branca - Cocaine

Castanha, Pó - Heroin

Cena - Drug

Dealer, Paiador, Passador, Traficante - Drug Dealer

Fumar uma chinesa - To use Heroin

Mandar um chuto - To send a Kick

Matar a ressaca - To kill the hangover

Smoke a Pipo - Smoking Cocaine

\footnotetext{
${ }^{10}$ Glamorization of drugs is a term used among technicians or people involved in the treatment of drug addiction. This term is used to describe the moments when drug addicts talk about the drug in a glamorous way, as if it were something very good, which provides a well-being that cannot be felt otherwise.
} 


\section{References:}

1. Água, L. d. (2016). $O$ "avião" dos anos 80 que nunca nos deixou. (P. Rios, \& I. Rocha, Entrevistadores) Rádio Renascença. Lisboa. Available http://rr.sapo.pt/especial/57186/lena_dagua_o_aviao_dos_anos_80_q ue_nunca_nos_deixou

2. Andrade, I. M. (1994). A face oculta das drogas. Porto: Porto Editora.

3. Ceron, M. (2012). Habilidades de Comunicação: Abordagem centrada na pessoa -Módulo Psicossocial. São Paulo: UNA-SUSUNIFESP.

4. Fernandes, S. F. (2007). As Perdas na Toxicodependência. Coimbra: ISMT. Available in: http://repositorio.ismt.pt/handle/123456789/201

5. Givhan, R. (1996). "Why Dole Frowns on Fashion". Los Angeles Times. Available in: http://articles.latimes.com/1996-08-08/news/1s32243_1_fashion-industry

6. IDT (2002). Guia de Sobrevivência às Drogas e às Noitadas -Linha SOS. Lisboa: SOS-Droga/Projeto de Vida.

7. Lacerda, L. E. (2014). Exercício profissional do assistente social: da imediaticidade às possibilidades históricas. Serviço Social e Sociedade, pp. 22-44. Availabe in: http://www.scielo.br/pdf/sssoc/n117/03.pdf

8. Lucchini, R. (1985). Drogues et société: essai sur la toxicodépendance. Fribourg: Fribourg: Editions Universitaires.

9. Marques, A. R. (2008). A(s) Drogas (s) E A(S) Toxicodependências (s)-Representações Sociais e Políticas em Portugal. (Dissertação de Mestrado em Desenvolvimento e Inserção Social). Porto: Universidade do Porto.

10. OMS (2010). Classificação Internacional de Doenças (CID). ICD-10 Version:2010. Available in:

http://apps.who.int/classifications/icd10/browse/2010/en\#

11. Silva, M. F. (2011). Consumo de drogas: O impacto da informação e do modelo de regulamentação nos comportamentos. (Dissertação de mestrado em Sociologia - Área de Especialização em Saúde e Sociedade). Braga: Universidade do Minho. Available in:https://repositorium.sdum.uminho.pt/bitstream/1822/16090/1/Mara $\% 20$ Fernandes \%20da\%20Silva.pdf

12. Silva, P. (2008) "A comunicação na prática médica: seu papel como componente terapêutico". Revista Portuguesa de Clínica Geral, 50512. Available in: http://dx.doi.org/10.32385/rpmgf.v24i4.10531 